\title{
Effect of gas saturation conditions on the expansion ratio of microcellular poly(lactic acid)/wood-flour composites
}

\author{
L. M. Matuana*1,2, O. Faruk ${ }^{2}$ \\ ${ }^{1}$ School of Packaging,Michigan State University, East Lansing, Michigan 48824, USA \\ ${ }^{2}$ Department of Forestry, Michigan State University, East Lansing, Michigan 48824, USA
}

Received 9 April 2010; accepted in revised form 20 June 2010

\begin{abstract}
Poly(lactic acid) or PLA and PLA/wood-flour composites were microcellular foamed with $\mathrm{CO}_{2}$ through a batch foaming process. Specifically, the gas saturation pressure and time varied during processing to produce PLA foams with a high expansion ratio. A ten fold expansion ratio resulted in microcellular foamed PLA over unfoamed counterpart. The foaming conditions associated with such a high expansion ratio involved a lower gas saturation pressure up to $2.76 \mathrm{MPa}$, which corresponds to a critical gas concentration of approximately $9.4 \%$. Beyond this critical value, foam expansion decreased significantly. Investigations also studied the effect of incorporating wood flour on the foamability of the resulting PLA/wood-flour composites. The addition of wood flour into the PLA matrix significantly affected the expansion ratio of PLA/wood-flour composite foams.
\end{abstract}

Keywords: biopolymers, biocomposites, microcellular foam, wood plastic composites, cell morphology

\section{Introduction}

Poly(lactic acid) or PLA, a plant-based biodegradable plastic, exhibits many properties equivalent to or better than many petroleum-based plastics. However, few commercial applications exist not only due to its lower impact resistance and higher cost than synthetic plastics, but also to having a narrow processing window [1].

Blending PLA with various additives such as lubricant, plasticizer or a second polymer assists in broadening its applications [2, 3]. Unfortunately, this approach could increase the manufacturing cost given the additional expenses associated with the additives [4]. Previous efforts to overcome the cost of PLA included blending with fillers such as cellulosic fibers [5]. However, the lowered cost due to filler addition is usually achieved at the expense of other properties such as the ductility (lower elongation at break) and lower impact resistance, because the incorporated brittle cellulosic fibers alter the ductile mode of failure of the matrix, making the composites more brittle than neat polymer [6-8]. Continuous efforts seek to further reduce the cost of PLA while enhancing its flexibility and toughness. Recently, Wong et al. [9] reported that plastics are one of the most consumed materials in the world and in typical plastics manufacturing processes, the material cost account for 50-70\% of the total production cost. Therefore, there is a significant economic interest to reduce material usage. The widely recognized foaming process, which includes microcellular plastics as an example, enhances the ductility and impact resistance of the polymer matrix, in addition to providing a significant expansion ratio and weight reduction in plastic parts $[10,11]$. The high expansion ratio induced by foaming succeeds in reducing the material cost and consumption in mass-produced plastic parts without a major compromise to the required properties $[10,11]$. Recently the production of microcellular-

*Corresponding author, e-mail: matuana@msu.edu

(C) BME-PT 
foamed structures in the polymer through a batch and continuous foaming processes has addressed several of the hindrances associated with PLA [4, 12-20].

Over the past years, several in-depth studies have examined the effects of the processing conditions and formulations on the foamability of PLA in a batch process [4, 12-20]. Fujimoto and coworkers described the foam processing of neat PLA and two different types of PLA/layered silicate nanocomposites using supercritical $\mathrm{CO}_{2}$ as a foaming agent [12]. The nanocomposite foams showed smaller cell size and larger cell-population density compared to neat PLA owing to the dispersed silicate particles which acted as nucleating sites for cell nucleation [12]. The concentration of organically modified layered silicates has also been shown to strongly affect the cell size and cell-population density of PLA and PLA nanocomposites [18, 19]. Compared with neat PLA, the nanocomposites foamed at $110^{\circ} \mathrm{C}$ using a $20: 80$ blend of $\mathrm{CO}_{2}: \mathrm{N}_{2}$ mixture as the blowing agent exhibited reduced cell size and increased cell-population density, due to the presence of the heterogeneous bubble nucleation sites. However, nanocomposites with higher organoclay content $(10 \%)$ was poorly foamed due to the intrinsically high viscosity and elasticity, caused by organoclay exfoliation and chain extension/branching, which reduce the cell growth [18]. Conditioning PLA with $\mathrm{CO}_{2}$ has been reported to induce crystallinity in the polymer and the degree of crystallinity of PLA increases with increasing saturation pressure $[14,15]$. The greatest increases in crystallinity under room temperature conditions was observed at pressures between 2.1 and $2.8 \mathrm{MPa}$, and this induced crystallinity significantly affected the PLA foamability. In fact, Hu et al. [15] reported that lower saturation pressure (up to $2.8 \mathrm{MPa}$ ) leads to more uniform microcellular structures whereas foam structures become inhomogeneous with an increase in saturation pressure, owing to the rapid diffusion of $\mathrm{CO}_{2}$ out of the polymer.

Attempts have also been made to enhance the foamability of PLA by controlling the melt rheology of PLA through increasing the molecular weight to compensate for the molecular weight decrease caused by processing degradation and to increase the melt viscosity $[19,20]$. PLA modified with chain extenders showed enhanced melt viscosity and elasticity, resulting in the production of foamed PLA with smaller cell size, higher cell-population density, and lower foam density compared to the unmodified counterpart $[19,20]$

In addition to the ingredients used in the PLA formulations, processing variables also affect the foamability of PLA. Investigations have shown that the foaming time and/or the foaming temperature are important process variables for controlling the density and porous morphology of PLA foams owing to their effects on the visco-elastic properties of the polymer [4]. Studying the dependence of the foam density on the foaming temperature under different $\mathrm{CO}_{2}$ pressures (14-30 MPa) for both neat PLA and PLA-based nanocomposites, Ema et al. [13] reported that the critical foaming temperature is around $140^{\circ} \mathrm{C}$ where the morphology of foamed samples changes from nanocellular to a microcellular structure. The competition between cell nucleation and cell growth accounts for these two distinct trends. Cell nucleation dominates at the low foaming temperature (up to $140^{\circ} \mathrm{C}$ ), owing to a large supply of $\mathrm{CO}_{2}$ molecules in the system coupled with the high viscosity of the matrix, which suppresses cell growth. By contrast, cell growth and coalescence occurs at higher foaming temperature $\left(>150^{\circ} \mathrm{C}\right)$ due to the low viscosity of the system [13].

Our previous study showed significant improvements in the volume expansion ratio (a two-fold expansion over unfoamed PLA), impact resistance (up to four-fold increase over unfoamed PLA), strain at break (up to two-fold increase over unfoamed PLA), and toughness (up to four-fold increase over unfoamed PLA) by creating foamed microcells in PLA samples. The results imply that foamed PLA exhibits enhanced ductility and impact resistance owing to the presence of microcells [4].

Although previous study indicates the successful creation of microcellular structures in PLA [4], a higher expansion ratio (greater than two-fold expansion over unfoamed PLA) remained unobtainable. The reasoning behind this result lays in the fact that some critical foaming conditions such as saturation pressure and time, which exert a strong influence on the foaming ability of the polymer matrix, stayed constant in our previous study [4]. Therefore, investigating the feasibility of producing a larger expansion ratio in PLA requires further studies. This study aims to investigate other 
parameters, in order to achieve the desired expansion ratio.

Furthermore, while demonstrations that clearly illustrate the importance of generating microcellular foamed structures in neat PLA as a means to improve its impact strength and reduce material consumption (through expansion) exist, the effect of incorporating cellulosic fibers on the foamability of the resulting PLA/wood-flour composites lacked investigation in our previous study. Improvements in the toughness of PLA by microcellular foaming resulted at the expense of the strength and stiffness, implying the need for using fibers to strengthen foamed samples. Therefore, this study also aimed at understanding the foamability of PLA filled with wood flour.

\section{Experimental}

\subsection{Materials}

The matrix consisted of a commercial grade PLA resin (PLA 8302D from NatureWorks ${ }^{\circledR}$ LLC, Minnetonka, MN, USA). The properties of this resin measured by the authors [21] include the following (a density of $1.257 \mathrm{~g} / \mathrm{cm}^{3}$, a percent crystallinity of $1.2 \%$, and a melt flow index of $6.5 \mathrm{~g} / 10 \mathrm{~min}$ $\left(190^{\circ} \mathrm{C}, 2.16 \mathrm{~kg}\right.$ dead load). Carbon dioxide acted as the foaming agent (commercial $99.5 \% \mathrm{~min}$ ). Wood flour from hardwood maple species (40mesh size) supplied by American Wood Fibers (Schofield, WI, USA) was used as filler. Gammaaminopropyltriethoxysilane (SCA 1100) supplied by Struktol (Stow, OH, USA) was used as coupling agent.

\subsection{Treatment of wood flour}

The use of coupling agents, which are important ingredients in the formulations of plastic/woodfiber composites, also has a significant effect during the foaming process of the composites [22]. Surface modification of wood fiber with a coupling agent has strong effects on both the concentration of gas molecules absorbed by the composites and the cell morphology of the foamed composites produced through a batch foaming process [6, 22]. Previous studies showed that a microcellular-foamed structure was better developed in the composites with treated wood fibers than in the composites with untreated fibers because the addition of cou- pling agent into the formulation helped encapsulate the gas in the composites for the cell growth [6, 22]. Consequently, silane was used as a coupling agent to enhance the adhesion between the matrix and the filler.

The silane coupling agent was mixed with wood flour in a $60 \mathrm{ml}$ electrically heated three-piece internal mixer/measuring head (3:2 gear ratio) with roller style mixing blades (C. W. Brabender Instruments Inc., South Hackensack, NJ, USA). The mixing process ran at a constant mixer temperature of $100^{\circ} \mathrm{C}$ for 3 minutes. The rotor speed ran at $50 \mathrm{rpm}$ with the weight charge set at $20 \mathrm{~g}$. A $5 \mathrm{~kg}$ dead weight rested on the top of the ram throughout the experiments. The silane coupling agent content remained at $1 \%$, based on the weight of wood flour in the composites [23].

\subsection{Manufacture of PLA and PLA/wood- flour composite films}

PLA and wood-flour treated with silane were directly blended in a kitchen mixer (Blender MX1050XTS from Warning Commercial Xtreme, Torrington, CT, USA) at $22000 \mathrm{rpm}$ for 1 minute. The amount of wood flour into the composites varied from 10 to $40 \mathrm{wt} \%$ based on the total weight of the composites. The compounded materials $(60 \mathrm{~g})$ were then fed into the internal mixer as described above for melt blending at $180^{\circ} \mathrm{C}$ for 5 minutes. The melted composites were then compressionmolded into panels (Erie Mill Co., Erie, Pennsylvania, USA) at $180^{\circ} \mathrm{C}$ and $3 \mathrm{MPa}$ constant pressure for 1 minute. The thickness of the panels measured around 1.5-2 mm. Manufacturing neat PLA films followed a similar process.

\subsection{Sorption and foaming experiments}

Sorption experiments performed on neat PLA used a gravimetric method as described in previous papers $[6,22]$. The main purpose of sorption experiments involves estimating the amount of gas absorbed in a polymer (or estimated gas solubility), one of the important factors in the gas foaming process $[6,22]$. During the foaming experiments, the number of bubbles nucleated depends strongly on the concentration of gas dissolved in the molten polymer matrix $[6,22]$. 
Compression-molded samples were cut into $1.27 \mathrm{~cm} \times 2.54 \mathrm{~cm}$ rectangular specimens. The original weights of these samples were measured using a digital balance readable to $0.0001 \mathrm{~g}$. The samples were then placed in a pressure chamber and saturated with $\mathrm{CO}_{2}$ at various pressures (1.38 to $5.52 \mathrm{MPa}$ or 200 to $800 \mathrm{psi}$ ) at room temperature for various periods of time (1-10 days). At the end of the saturation, the $\mathrm{CO}_{2}$-saturated samples were removed from the pressure chamber and rapidly weighed again on the balance to determine the amount of $\mathrm{CO}_{2}$ absorbed (measured solubility). The weight gain percent of $\mathrm{CO}_{2}$ was obtained by calculating the difference between the two weights. It should be pointed out that the loss of blowing agent in a batch foam processing used in this study is unavoidable. Nevertheless, the weight gain was measured within few seconds after removing saturated samples from the pressure vessel to minimize the gas escape to the environment.

Producing microcellular-foamed structures in the neat PLA samples required subjecting the $\mathrm{CO}_{2}$-saturated samples to a rapid pressure drop and a rapid temperature increase that resulted in nucleation and growth of gas nuclei. This was achieved by taking the specimens out of the pressure chamber and heating them above their glass transition temperature using a well-controlled temperature bath at $150^{\circ} \mathrm{C}$ for 5 seconds. After foaming, the samples were kept in air for 10 seconds for cell growth and then immediately dipped into a water bath to freeze the foam structure and minimize the deterioration of cells through cell coalescence during bubble growth $[4,6,22]$.

Composite samples were also foamed at $150^{\circ} \mathrm{C}$ for 5 seconds, but the samples were saturated at $2.76 \mathrm{MPa}$ (400 psi) for 4 days based on sorptions isotherms, which will be discussed later on.

\subsection{Characterization of microcellular foamed samples}

The densities of the unfoamed $\left(\rho_{u}\right)$ and foamed $\left(\rho_{f}\right)$ samples measured according to ASTM standard D792 (Buoyancy method) involved measuring the weights of at least five randomly selected samples for each formulation in the air $\left(m_{1}\right)$ and in n-hexane $\left(m_{2}\right)$. Determining the density of the material (Equation 1), the void fraction $\left(V_{f}\right)$ (Equation 2) or equivalently the density reduction, and the volume expansion ratio $(\phi)$ (Equation 3) used the following equations, respectively:

$$
\begin{aligned}
& \text { density }=\frac{m_{1} \cdot \rho_{F L}}{m_{1}-m_{2}} \\
& V_{f}=\frac{\rho_{u}-\rho_{f}}{\rho_{u}} \cdot 100 \\
& \phi=\frac{\rho_{u}}{\rho_{f}}=\frac{1}{1-V_{f}}
\end{aligned}
$$

with $\rho_{F L}$ as the density of $\mathrm{n}$-hexane $\left(0.6594 \mathrm{~g} / \mathrm{cm}^{3}\right)$. Scanning electron microscope (SEM) images obtained from a JEOL 6300F FESEM at $10 \mathrm{kV}$ aided in observing and analyzing the cellular morphology of the foamed PLA samples. Gold-coating the fractured surfaces of foamed samples preceded to SEM analysis.

\section{Results and discussion}

\subsection{Sorption behaviors of $\mathrm{CO}_{2}$ in PLA}

Although the aim of this study was to produce microcellular foam in PLA/wood-flour composites, it is paramount to first understand the effect of saturation conditions on the foamability of neat PLA since the gas does not dissolve in wood particles, i.e., PLA is the only component of the composite that can be foamed.

The amount of sorbed $\mathrm{CO}_{2}$ in neat PLA was determined as a function of the saturation pressures (from 1.38 to $5.52 \mathrm{MPa}$ or from 200 to $800 \mathrm{psi}$ ) and times (1-10 days) at room temperature. Figures 1a and $1 \mathrm{~b}$ show the sorption isotherms obtained in these experiments and the effect of the gas saturation pressure (10 days saturation time) on the amount of gas dissolved in the matrix, respectively. The gas content in the polymer followed Henry's law and remained directly proportional to the gas pressure (Figure 1) [4]. This trend was expected because by increasing pressure, the gas molecules are forced between polymer chains, expanding the space between molecules and thus increasing their mobility, which allow more gas molecules to be absorbed [24]. The amount of $\mathrm{CO}_{2}$ (or measured solubility of $\mathrm{CO}_{2}$ ) in PLA measured significantly higher $(21.1 \%)$ when compared to other glassy matrices such as PVC (8.6\%) and PS (0.8\%) [4]. The Lewis acid-base intermolecular interactions where the carbonyl groups of PLA act as an elec- 

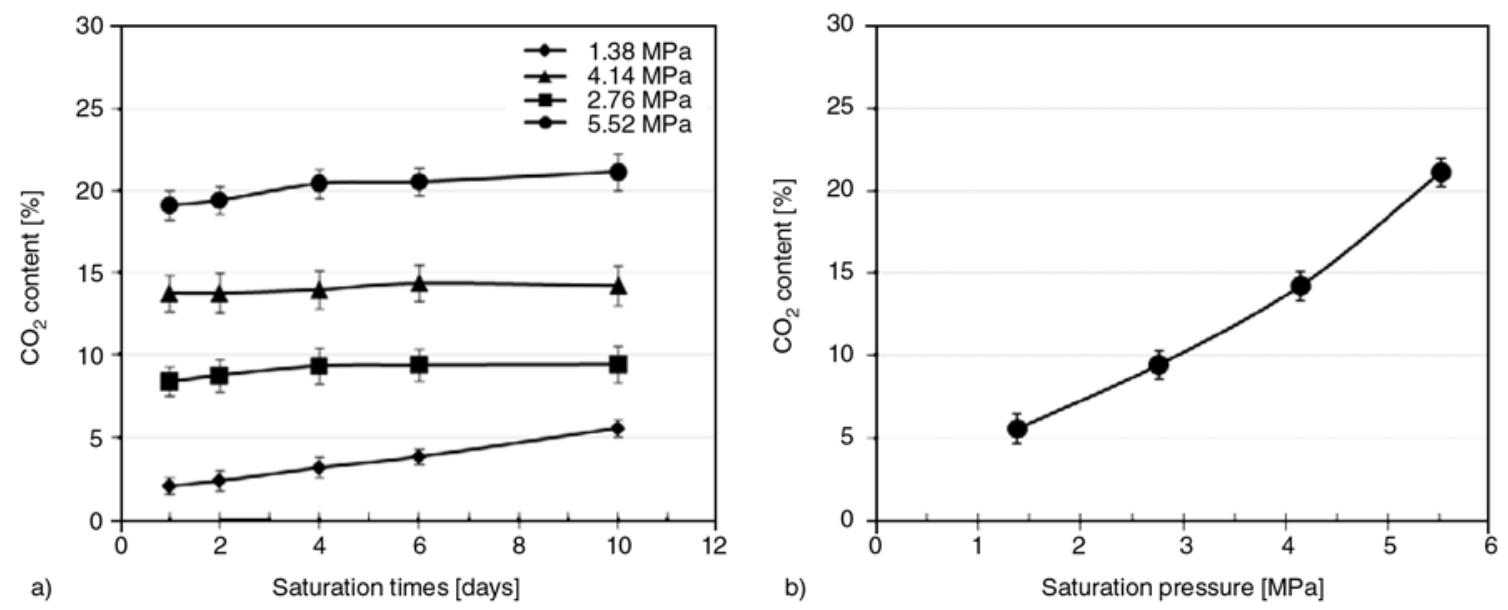

Figure 1. (a) $\mathrm{CO}_{2}$ concentration in PLA as function of saturation pressure (1.38 to $5.52 \mathrm{MPa}$ ) and saturation time (1-10 days) and (b) $\mathrm{CO}_{2}$ content vs. saturation pressure (10 days saturation time) measured at room temperatures. The trend line option in Figure $1 \mathrm{~b}$ was set as linear and intercept at zero.

tron donor and carbon dioxide acts as an electron acceptor produced this anticipated effect. Moreover, this type of interaction where the polar groups in the polymers provide more sites for $\mathrm{CO}_{2}$ mole-

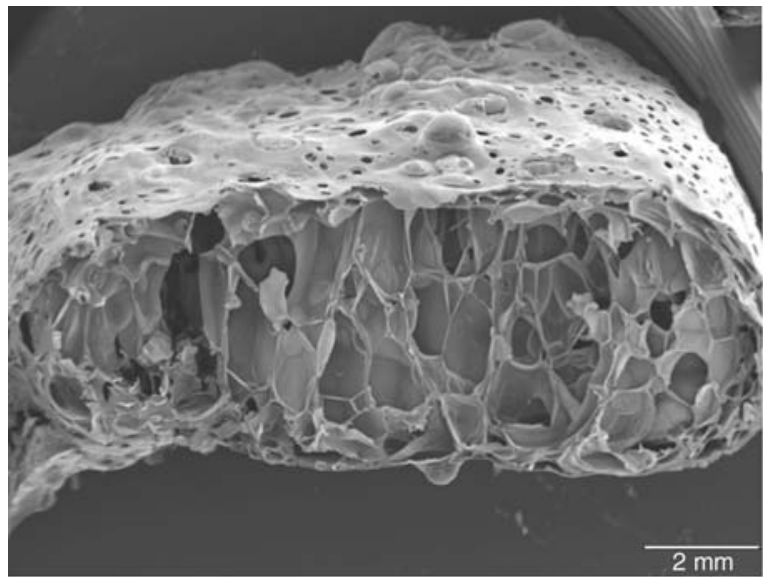

a)

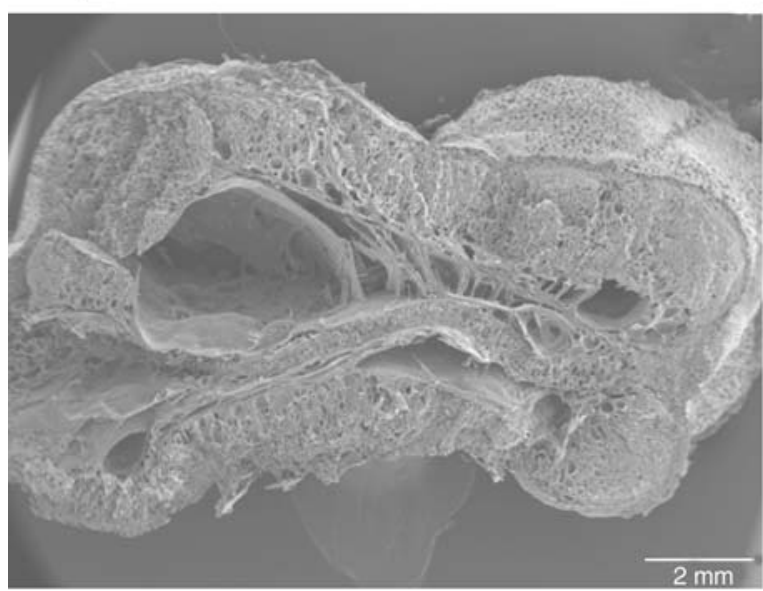

c) cules was previously shown by other investigators [24-28].

Although the amount of $\mathrm{CO}_{2}$ dissolved in PLA increased as the saturation pressure increased, irre-

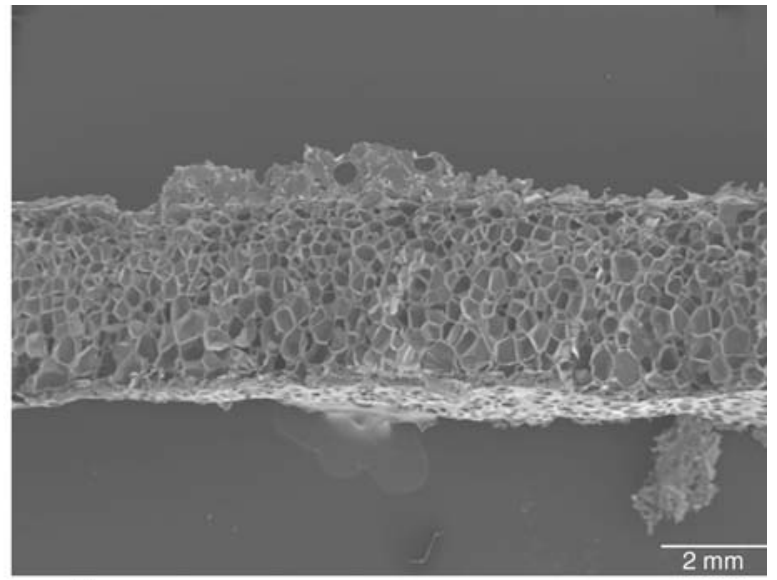

b)

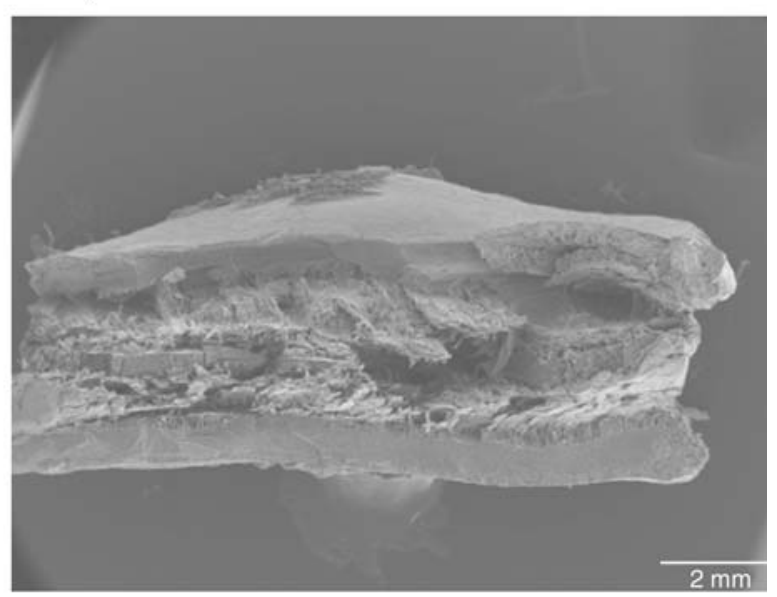

d)

Figure 2. Effect of saturation pressure on the cellular structures of PLA: (a) $1.38 \mathrm{MPa}$, (b) $2.76 \mathrm{MPa}$, (c) 4.14 MPa, (d) $5.52 \mathrm{MPa}$ for 10 days, magnification (10x) 
spective of the saturation duration (Figure 1a), the amount of $\mathrm{CO}_{2}$ absorbed by neat PLA, however, only acted as a strong function of saturation time at lower saturation pressures (up to $2.76 \mathrm{MPa}$ or $400 \mathrm{psi}$ ). Absorbing the large amount of $\mathrm{CO}_{2}$ when saturated at lower pressure required a longer saturation time for PLA. As seen in Figure 1a, the $\mathrm{CO}_{2}$

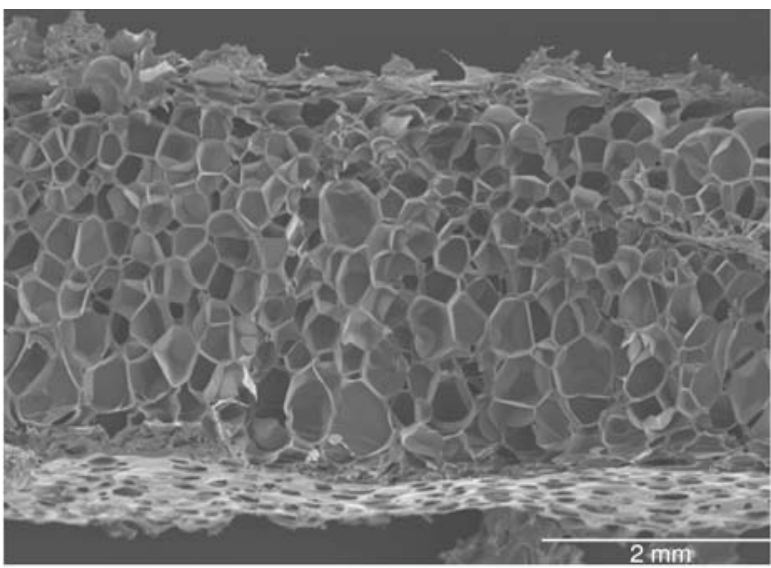

a)

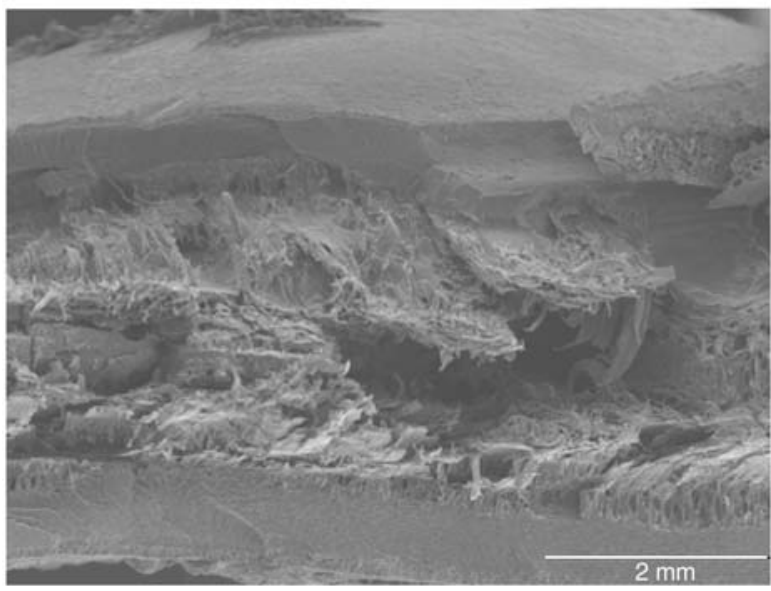

c)

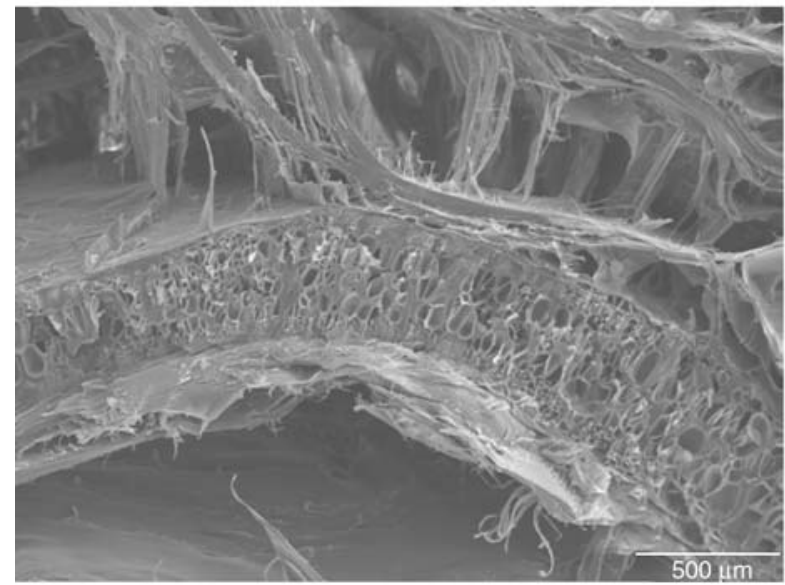

e) content in the PLA at $1.38 \mathrm{MPa}(200 \mathrm{psi})$ doubled when the saturation time increased from 1 to 10 days, implying that the longer the polymer is exposed to $\mathrm{CO}_{2}$, the greater the absorbed $\mathrm{CO}_{2}$ amount by the polymer as expected from the Fick's law of diffusion [22]. Similar trends were reported by other investigators [29].

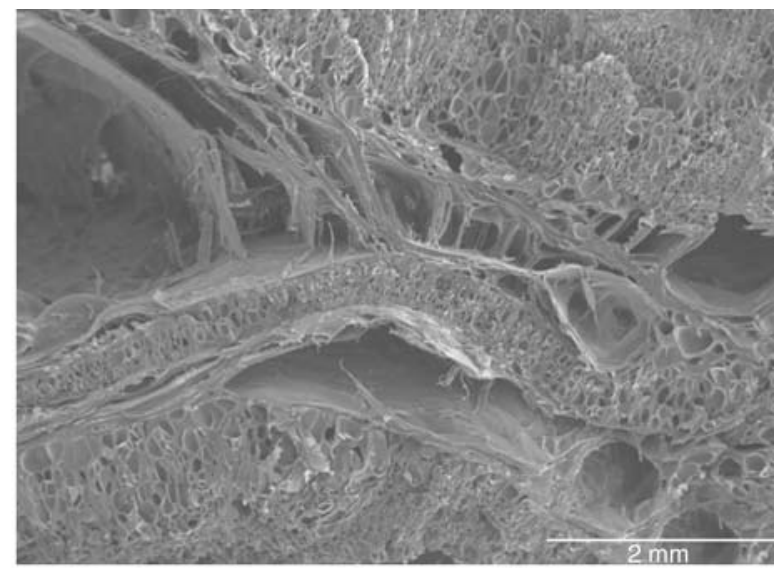

b)

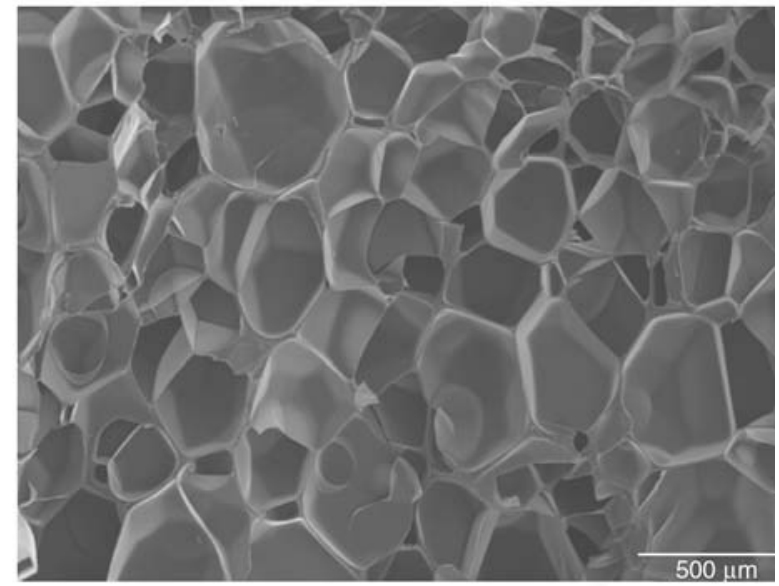

d)

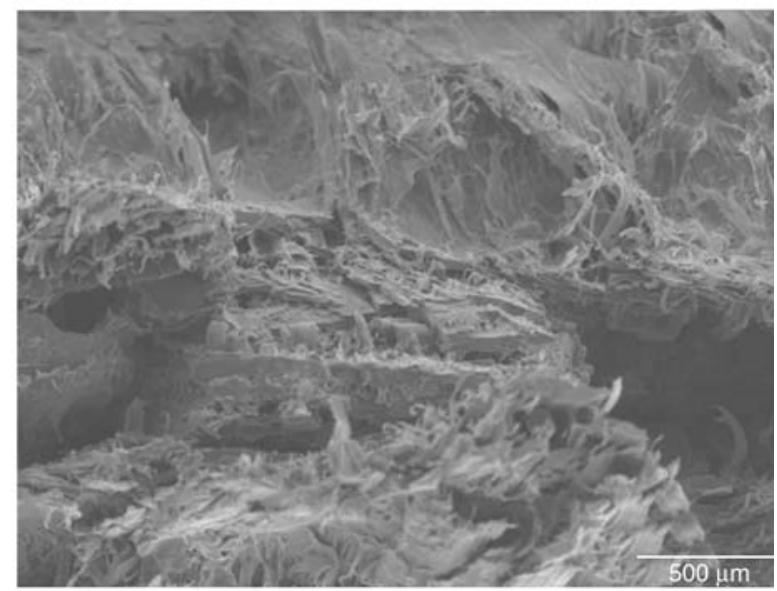

f)

Figure 3. Effect of saturation pressure on the cellular structures of PLA: (a, d) 2.76 MPa, (b, e) 4.14 MPa, (c, f) 5.52 MPa for 10 days. SEM for images a, b, c and for images d,e, f were taken at low magnification $(20 x)$ and high magnification $(50 \times)$, respectively 


\subsection{Morphology and expansion ratio of microcellular neat PLA}

Figures 2 and 3 illustrate the effect of $\mathrm{CO}_{2}$ saturation pressure on the cellular morphology of microcellular foamed neat PLA. A lower saturation pressure $(1.38 \mathrm{MPa})$ produced larger cells compared to higher saturation pressures. Overall, the lower saturation pressures (up to $2.76 \mathrm{MPa}$ ) resulted in more uniform microcellular structures. Higher saturation pressure resulted in the structures becoming inhomogeneous and drastically deteriorated, owing to the polymer's rapid diffusion of $\mathrm{CO}_{2}$ and the $\mathrm{CO}_{2}$-induced crystallization in PLA from the plasticizing effect of gas at high concentrations $[15,30]$.

These results correlated with those reported by other investigators who found that an optimal saturation pressure for foaming PLA exists. For example, Hu and coworkers [15] measured the degree of crystallinity of PLA [a copolymer of poly-L-lactic acid (PLLA) and poly-DL-lactic acid (PDLLA)] conditioned with $\mathrm{CO}_{2}$ at room temperature and pressures up to $5.8 \mathrm{MPa}$. They found that the degree of crystallinity increases with increasing saturation pressure [15]. In fact, lower saturation pressure (up to $2.8 \mathrm{MPa}$ ) led to more uniform microcellular structures with cell diameters on the order of $30-40 \mu \mathrm{m}$ and a cell density of $7.93 \cdot 10^{7} \mathrm{cell} / \mathrm{cm}^{3}$. By contrast, foam structures became inhomogeneous and cell size decreased with an increase in saturation pressure, owing to the rapid diffusion of $\mathrm{CO}_{2}$ out of the polymer. As a result, the density of the foamed sample was almost similar to that of unfoamed material $[15,30]$.

Furthermore, it is recognized that the solubility and diffusivity of gas in semi-crystalline polymers are a function of the degree of crystallinity because gas does not dissolve in the crystallites [22, 31-33]. Increasing the mass fraction of crystallite in the polymer leads to the reduction of the amorphous matrix mass fraction. As a result, the solubility and diffusivity of gas are reduced since the gas does not dissolve in the crystallites, and the crystallites tend to obstruct the movement of gas molecules in the polymer [22]. Since the crystal domains in semicrystalline polymer do not absorb gas, induced crystallinity in PLA by increasing the gas saturation pressure may have reduced the amount of gas available in the amorphous region due to the lower

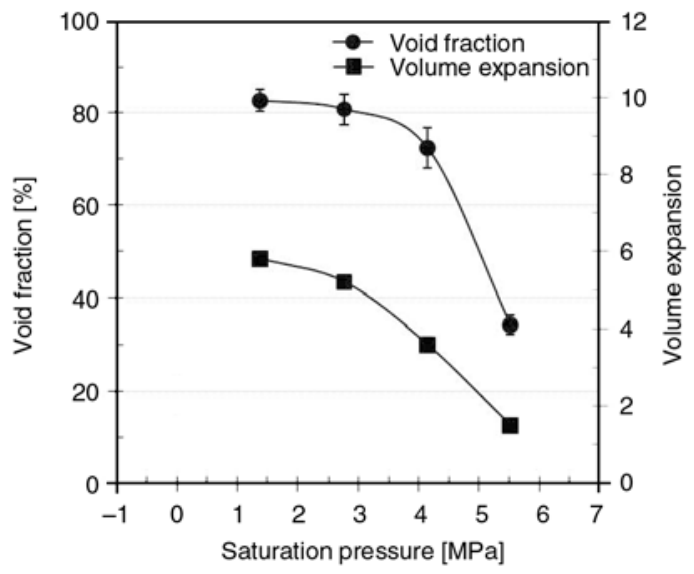

Figure 4. Influence of saturation pressure on the void fraction and volume expansion ratio of neat PLA foams. Samples were saturated for 10 days. Error bars did not appear in the graph due to the smaller values of standard deviations.

amorphous volume fraction, thus affecting the morphology developed in the foamed PLA samples saturated at higher pressure (Figures $2 \mathrm{c}$ and $2 \mathrm{~d}$ ).

Figure 4 shows the effect of saturation pressure on the void fraction and volume expansion ratio. Higher volume fraction and expansion ratio were achieved, but they remained almost constant as the gas saturation pressure increased up to $2.76 \mathrm{MPa}$. However, above $2.76 \mathrm{MPa}$, both the void fraction and the expansion ratio were directly proportional to the gas pressure; they decreased as the gas saturation pressure increased. The results suggest the need for a critical gas concentration of approximately $9.4 \%$ for significant foam expansion to occur. Increasing the concentration of $\mathrm{CO}_{2}$ beyond this critical value had a deleterious effect on the volume expansion, i.e., foam expansion remained low. The results imply the potential for achieving a higher expansion ratio in microcellular PLA foams conditioned at lower saturation pressure (e.g., up to $2.76 \mathrm{MPa}$ ) that corresponds to a critical gas concentration of approximately $9.4 \%$. At this condition, the saturation time of 4 days will be required for $\mathrm{CO}_{2}$ diffusion in the samples (Figure 1a).

\subsection{Morphology and expansion ratio of microcellular foamed PLA/wood-flour composites}

Figures 5 and 6 illustrate the effect of wood flour content on the cellular structures of PLA/woodflour composites, whereas Figure 7 shows the 
influence of wood flour content on the void fraction and volume expansion ratio. The samples were saturated at $2.76 \mathrm{MPa}$ (400 psi) for 4 days and foamed at $150^{\circ} \mathrm{C}$ for $5 \mathrm{sec}$. Lower saturation pressure was selected since it produced foamed PLA specimens with homogeneous morphology (Figures 2 and 3) and high volume expansion (Figure 4).

All microcellular foamed PLA/wood-flour composite samples had cells with finer average size

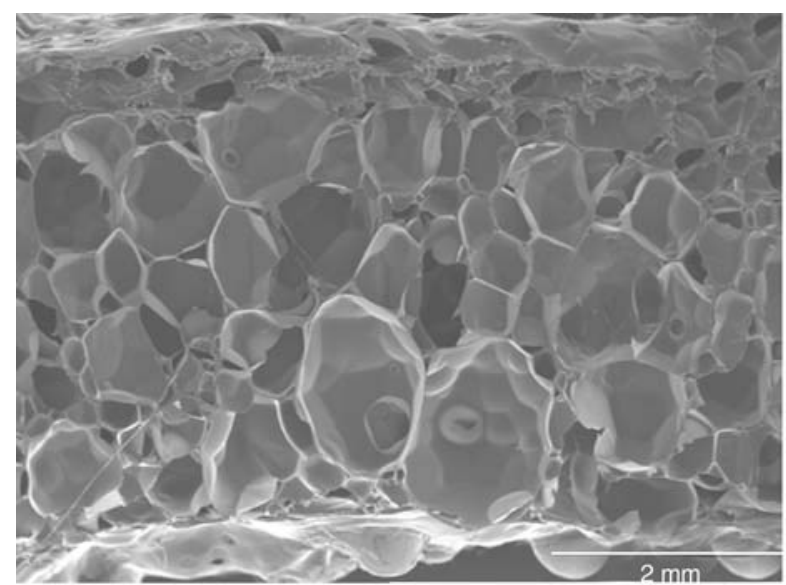

a)

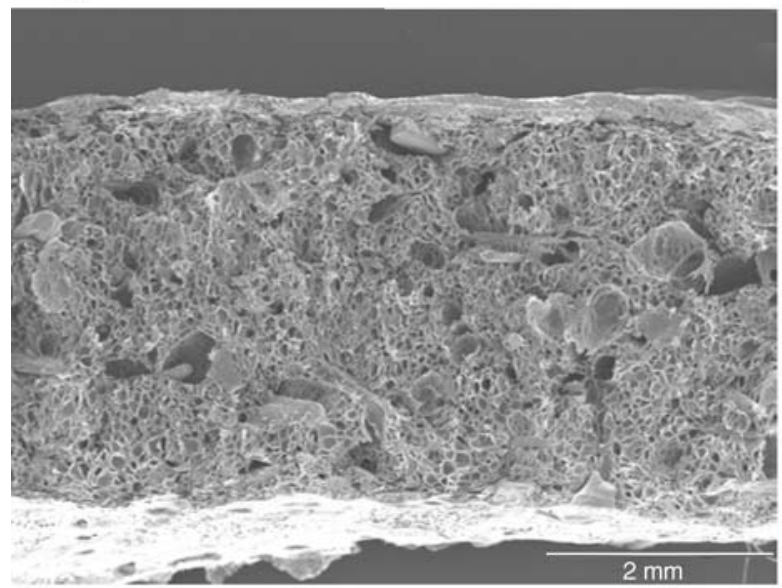

c) than their neat PLA counterpart (Figures 5 and 6). The cell size decreased further as the wood flour content increased in the matrix. The incorporation of wood flour into the PLA matrix produced this expected effect, as it increased the melt viscosity of the matrix and made the composites stiffer than the unfilled PLA, which provided high resistance to the cell growth in the polymer matrix [6,34-38].

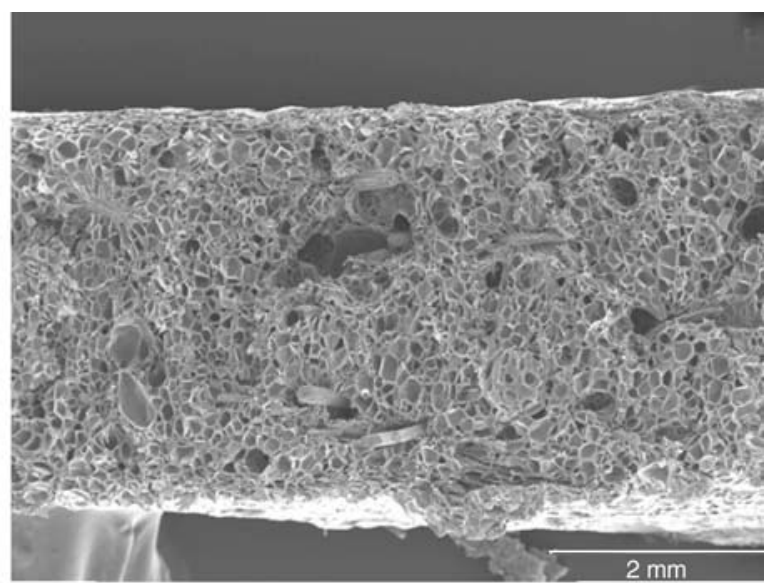

b)

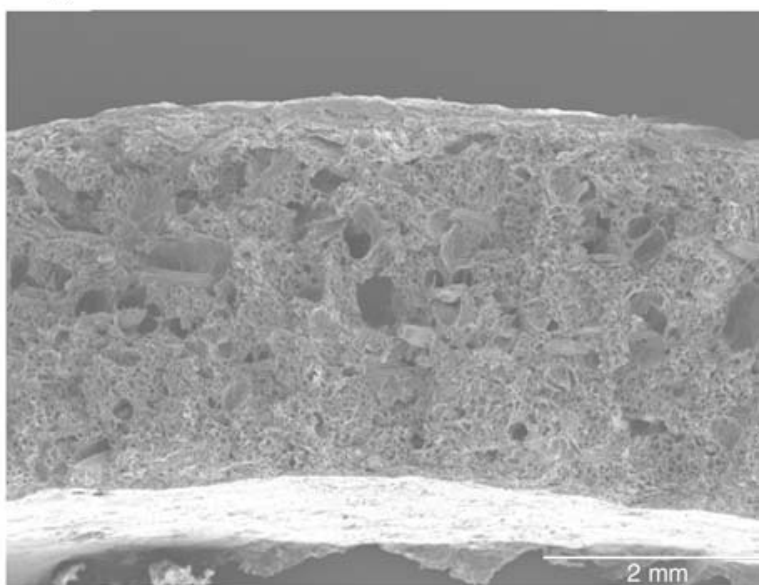

d)

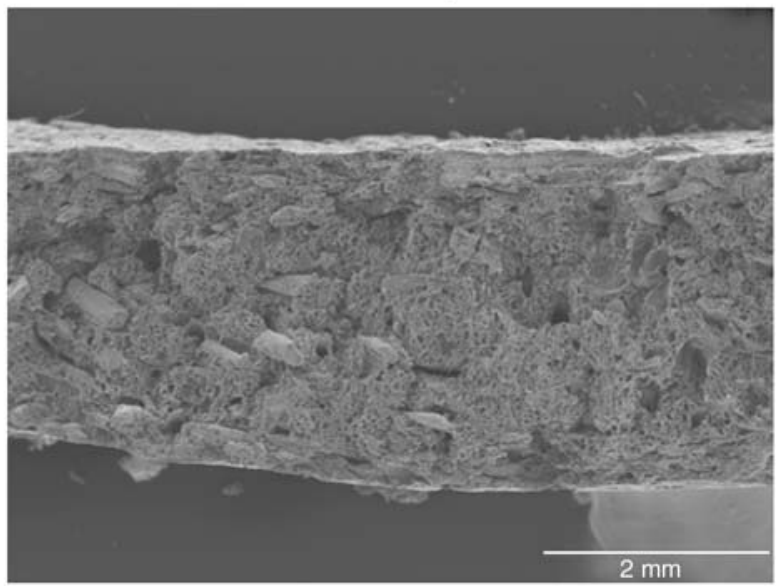

e)

Figure 5. Effect of wood flour content on the cellular structures of PLA: (a) $0 \mathrm{wt} \%$, (b) $10 \mathrm{wt} \%$, (c) $20 \mathrm{wt} \%$, (d) $30 \mathrm{wt} \%$, (e) $40 \mathrm{wt} \%$, saturation pressure $2.76 \mathrm{MPa}$ for 4 days, magnification $(20 \times)$ 


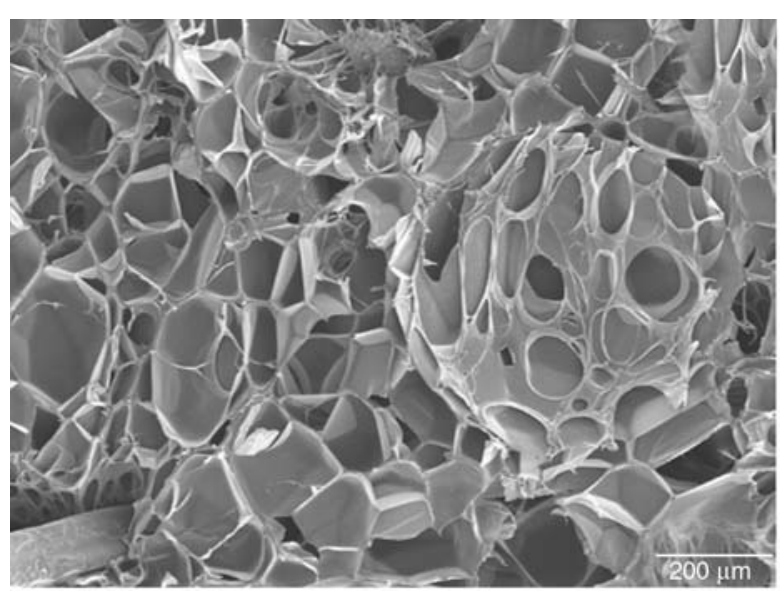

a)

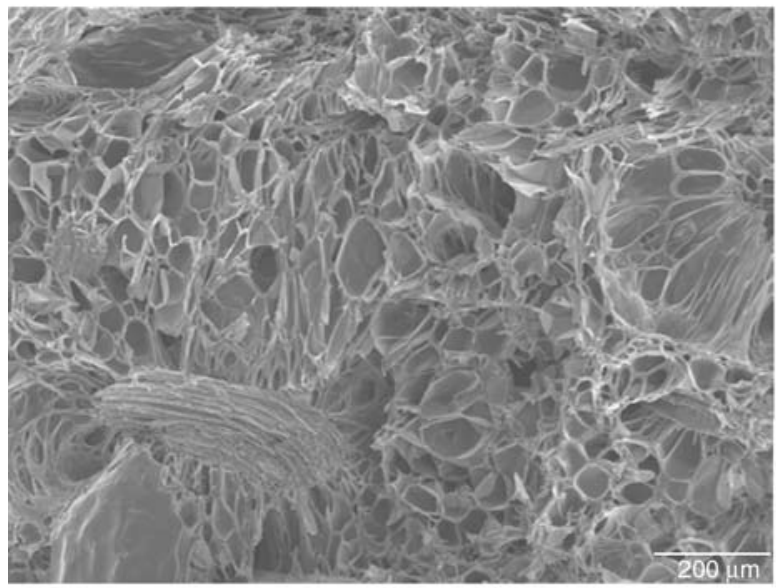

c)

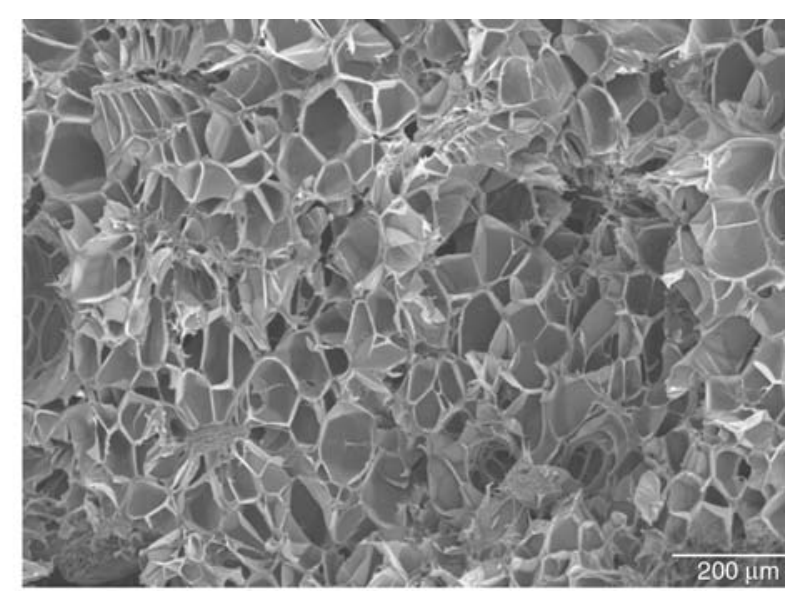

b)

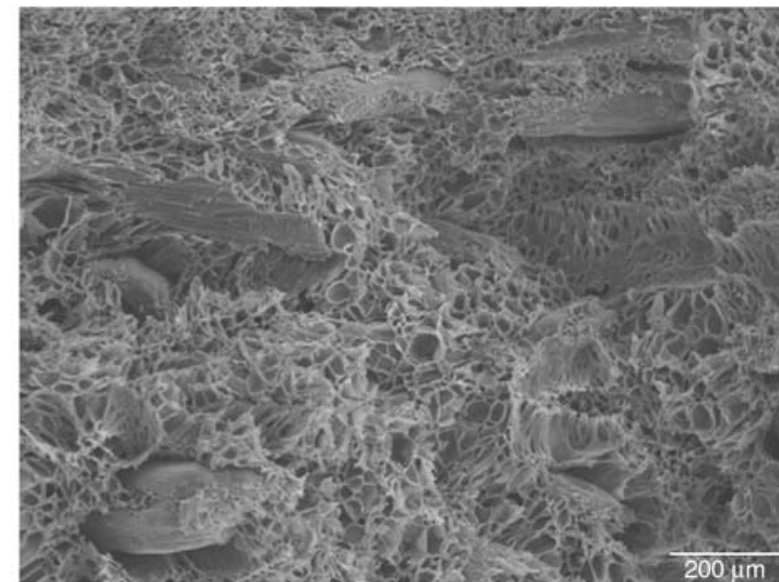

d)

Figure 6. Effect of wood fiber content on the cellular structures of PLA: (a) $10 \mathrm{wt} \%$, (b) $20 \mathrm{wt} \%$, (c) $30 \mathrm{wt} \%$, (d) $40 \mathrm{wt} \%$, saturation pressure $2.76 \mathrm{MPa}$ for 4 days, magnification (100×)

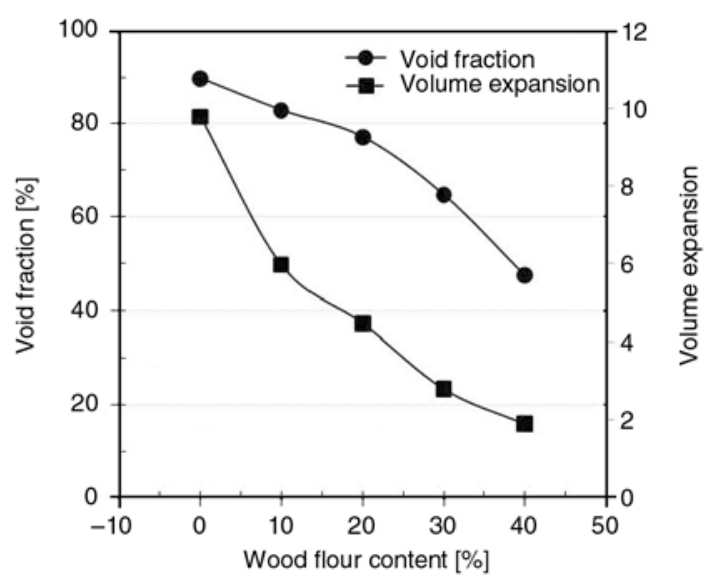

Figure 7. Effect of wood fiber content on the void fraction and volume expansion ratio of PLA/wood-flour composites foams. Samples were saturated at $2.76 \mathrm{MPa}$ for 4 days.

Observations also suggest that the addition of wood flour into the PLA matrix significantly affected the expansion ratio (void fraction) of PLA/wood-flour composite foams. As illustrated in Figure 7, increasing the wood flour content in the PLA matrix tended to noticeably decrease the expansion ratio of PLA in foamed samples. The anticipation of this tendency can be attributed not only to the number of nucleated cells and their growth, which controls the volume expansion ratio (or void fraction) during the foaming process but also to the strong dependency on the amount of gas molecules dissolved in the material as well as the volume fraction of the matrix in the composite [6, 34-38]. Our previous study showed that increasing wood flour content in the composites tends to decrease the volume fraction of the matrix in the composites [22]. Consequently, with a noticeably lowered amount of gas absorbed by the composite samples during foaming than that absorbed by neat plastic $[6,34$, 37], coupled with the decreased fraction of the matrix available for gas diffusion, the volume expansions in the composites also remained far inferior to those in the unfilled PLA foams. 


\section{Conclusions}

The influence of gas saturation conditions was assessed to produce microcellular foamed PLA with a high expansion ratio. In addition, this study examined the effect of incorporating wood flour on the foamability of the resulting PLA/wood-flour composites. The experimental results produce the following conclusions:

Microcellular PLA foams have the potential for a larger void fraction (up to $82 \%$ density reduction) and higher expansion ratio (ten fold expansion over unfoamed PLA). The foaming conditions associated with such an elevated expansion ratio involved a lower gas saturation pressure up to $2.76 \mathrm{MPa}$, which corresponds to a critical gas concentration of approximately $9.4 \%$. Increasing the concentration of $\mathrm{CO}_{2}$ beyond this critical value had a deleterious effect on the volume expansion, i.e., foam expansion decreased significantly.

The addition of wood flour into the PLA matrix significantly affected the expansion ratio (void fraction) of PLA/wood-flour composite foams. Increasing the wood flour content in the PLA tended to noticeably decrease the expansion ratio of PLA in foamed samples.

\section{Acknowledgements}

This project was partially supported by the National Research Initiative of the USDA Cooperative State Research, Education and Extension Service, grant number 2006-35504-17414.

\section{References}

[1] Kramschuster A., Pilla S., Gong S., Chandra A., Turng L-S.: Injection molded solid and microcellular polylactide compounded with recycled paper shopping bag fibers. International Polymer Processing, 22, 436-445 (2007). DOI: $\underline{10.3139 / 217.2063}$

[2] Mihai M., Huneault M. A., Favis B. D., Li H.: Extrusion foaming of semi-crystalline PLA and PLA/thermoplastic starch blends. Macromolecular Bioscience, 7, 907-920 (2007).

DOI: $\underline{10.1002 / \mathrm{mabi} .200700080}$

[3] Baiardo M., Frisoni G., Scandola M., Rimelen M., Lips D., Ruffieux K., Wintermantel E.: Thermal and mechanical properties of plasticized poly(L-lactic acid). Journal of Applied Polymer Science, 90, 17311738 (2003). DOI: $\underline{10.1002 / a p p .12549}$
[4] Matuana L. M.: Solid state microcellular foamed poly(lactic acid): Morphology and property characterization. Bioresource Technology, 99, 3643-3650 (2008). DOI: $\underline{10.1016 / \text { j.biortech.2007.07.062 }}$

[5] Pilla S., Gong S., O’Neil E., Rowell R. M., Krzysik A. M.: Polylactide-pine wood flour composites. Polymer Engineering and Science, 48, 578-587 (2008). DOI: $10.1002 /$ pen.20971

[6] Matuana L. M., Park C. B., Balatinecz J. J.: Processing and cell morphology relationships for microcellular foamed PVC/wood-fiber composites. Polymer Engineering and Science, 37, 1137-1147 (1997). DOI: $10.1002 /$ pen. 11758

[7] Matuana L. M., Park C. B., Balatinecz J. J.: The effect of low levels of plasticizer on the rheological and mechanical properties of polyvinyl chloride/newsprintfiber composites. Journal of Vinyl and Additive Technology, 3, 265-273 (1997). DOI: $10.1002 /$ vnl.10204

[8] Matuana L. M., Woodhams R. T., Balatinecz J. J., Park C. B.: Influence of interfacial interactions on the properties of PVC/cellulosic fiber composites. Polymer Composites, 19, 446-455 (1998). DOI: $10.1002 / p c .10119$

[9] Wong A., Leung S. N., Hasan M. M., Park C. B.: The foamability of polypropylene copolymer blown with argon, nitrogen and helium. in 'SPE ANTEC Technical Papers, Milwaukee, USA' 2551-2555 (2008).

[10] Martini-Vvedensky J. E., Waldman F. A., Suh N. P.: The production and analysis of microcellular thermoplastic foam. in 'SPE ANTEC Technical Papers, San Francisco, USA' 674-676 (1982).

[11] Martini J. E., Suh N. P., Waldman F. A.: Microcellular closed cell foams and their method of manufacture. U.S. Patent 4473665, USA (1984).

[12] Fujimoto Y., Ray S. S., Okamoto M., Ogami A., Yamada K., Ueda K.: Well-controlled biodegradable nanocomposite foams: From microcellular to nanocellular. Macromolecular Rapid Communications, 24, 457-461 (2003). DOI: $10.1002 /$ marc. 200390068

[13] Ema Y., Ikeya M., Okamoto M.: Foam processing and cellular structure of polylactide-based nanocomposites. Polymer, 47, 5350-5359 (2006). DOI: $10.1016 /$ j.polymer.2006.05.050

[14] Liao X., Nawaby A. V., Whitfield P., Day M., Champagne M., Denault J.: Layered open pore poly(L-lactic acid) nanomorphology. Biomacromolecules, 7, 2937 2941 (2006). DOI: $10.1021 / \mathrm{bm} 060738 \mathrm{u}$

[15] Hu X., Nawaby A. V., Naguib H. E., Day M., Ueada K., Liao X.: Polylactic acid (PLA)- $\mathrm{CO}_{2}$ foams at subcritical conditions. in 'SPE ANTEC Technical Papers, Boston, USA' 2670-2673 (2005).

[16] Wang X., Kumar V., Li W.: Low density sub-critical $\mathrm{CO}_{2}$-blown solid-state PLA foams. Cellular Polymers, 26, 11-35 (2007). 
[17] Matuana L. M., Diaz C. A.: Study of cell nucleation in microcellular poly(lactic acid) foamed with supercritical $\mathrm{CO}_{2}$ through a continuous-extrusion process. Industrial and Engineering Chemistry Research, 49, 2186-2193 (2010). DOI: $10.1021 /$ ie9011694

[18] Di Y., Iannace S., Di Maio E., Nicolais L.: Poly(lactic acid)/organoclay nanocomposites: Thermal, rheological properties and foam processing. Journal of Polymer Science Part B: Polymer Physics, 43, 689-698 (2005).

DOI: $10.1002 /$ polb.20366

[19] Marrazzo C., Di Maio E., Iannace S.: Foaming of synthetic and natural biodegradable polymers. Journal of Cellular Plastics, 43, 123-133 (2007).

DOI: $10.1177 / 0021955 X 06073214$

[20] Di Y., Iannace S., Di Maio E., Nicolais E.: Reactively modified poly(lactic acid): Properties and foam processing. Macromolecular Materials and Engineering, 290, 1083-1090 (2005).

DOI: $10.1002 /$ mame.200500115

[21] Matuana L. M., Faruk O., Diaz C. A.: Cell morphology of extrusion foamed poly(lactic acid) using endothermic chemical foaming agent. Bioresource Technology, 100, 5947-5954 (2009). DOI: $10.1016 /$ j.biortech.2009.06.063

[22] Matuana-Malanda L., Park C. B., Balatinecz J. J.: Characterization of microcellular $\mathrm{PVC} /$ cellulosicfibre composites. Journal of Cellular Plastics, 32, 449-469 (1996). DOI: $10.1177 / 0021955 X 9603200503$

[23] Matuana L. M., Balatinecz J. J., Park C. B., Sodhi R. N. S.: X-ray photoelectron spectroscopy study of silane-treated newsprint-fibers. Wood Science and Technology, 33, 259-270 (1999).

DOI: $\underline{10.1007 / \mathrm{s} 002260050114}$

[24] Aionicesei E., Škerget M., Knez Z.: Measurement of $\mathrm{CO}_{2}$ solubility and diffusivity in poly(L-lactide) and poly(D,L-lactide-co-glycolide) by magnetic suspension balance. The Journal of Supercritical Fluids, 47, 296-301 (2008).

DOI: $\underline{10.1016 / \text { j.supflu.2008.07.011 }}$

[25] Nalawade S. P., Picchioni F., Marsman J. H., Janssen L. P. B. M.: The FT-IR studies of the interactions of $\mathrm{CO}_{2}$ and polymers having different chain groups. The Journal of Supercritical Fluids, 36, 236-244 (2006). DOI: $10.1016 /$ j.supflu.2005.06.005

[26] Nalawade S. P., Picchioni F., Marsman J. H., Grijpma D. W., Feijen J., Janssen L. P. B. M.: Intermolecular interactions between carbon dioxide and the carbonyl groups of polylactides and poly( $\varepsilon$-caprolactone). Journal of Controlled Release, 116, 38-40 (2006).

DOI: $10.1016 /$ j.jconrel.2006.09.038
[27] Kazarian S. G., Vincent M. F., Bright F. V., Liotta C. L., Eckert C. A.: Specific intermolecular interaction of carbon dioxide with polymers. Journal of the American Chemical Society, 118, 1729-1736 (1996).

DOI: $10.1021 / \mathrm{ja} 950416 \mathrm{q}$

[28] Shieh Y-T., Liu K-H.: The effect of carbonyl group on sorption of $\mathrm{CO}_{2}$ in glassy polymers. The Journal of Supercritical Fluids, 25, 261-268 (2003). DOI: $\underline{10.1016 / \mathrm{S} 0896-8446(02) 00145-6}$

[29] Goel S. K., Beckman E. J.: Generation of microcellular polymeric foams using supercritical carbon dioxide. I: Effect of pressure and temperature on nucleation. Polymer Engineering and Science, 34, 1137 1147 (1994).

DOI: $10.1002 /$ pen.760341407

[30] Hao A., Geng Y., Xu Q., Lu Z., Yu L.: Study of different effects on foaming process of biodegradable PLA/ starch composites in supercritical/compressed carbon dioxide. Journal of Applied Polymer Science, 109, 2679-2686 (2008).

DOI: $10.1002 / a p p .27861$

[31] Michaels A. S., Bixler H. J.: Solubility of gases in polyethylene. Journal of Polymer Science, 50, 393 412 (1961). DOI: $10.1002 /$ pol.1961.1205015411

[32] Michaels A. S., Bixler H. J.: Flow of gases in polyethylene. Journal of Polymer Science, 50, 413-439 (1961). DOI: $10.1002 /$ pol.1961.1205015412

[33] Van Krevelen D. W.: Properties of polymers. Elesevier Science Publishers, New York (1990).

[34] Li Q., Matuana L. M.: Foam extrusion of high density polyethylene/wood-flour composites using chemical foaming agent. Journal of Applied Polymer Science, 88, 3139-3150 (2003). DOI: $10.1002 / a p p .12003$

[35] Matuana L. M., Li Q.: A factorial design applied to the extrusion foaming of polypropylene/wood-flour composite foams. Cellular Polymers, 20, 115-130 (2001).

[36] Matuana L. M., Li Q.: Statistical modeling and response surface optimization of extruded HDPE/ wood-flour composite foams. Journal of Thermoplastics Composite Materials, 17, 185-199 (2004). DOI: $10.1177 / 0892705704035404$

[37] Mengeloglu F., Matuana L. M.: Foaming of rigid PVC/wood-flour composites through a continuous extrusion process. Journal of Vinyl and Additive Technology, 7, 142-148 (2001). DOI: $10.1002 / \mathrm{vnl} .10282$

[38] Matuana L. M., Mengeloglu F.: Manufacture of rigid PVC/wood-flour composite foams using moisture contained in wood as foaming agent. Journal of Vinyl and Additive Technology, 8, 264-270 (2002). DOI: $10.1002 / \mathrm{vnl} .10373$ 